\title{
"DISPOSITIO, CELERITAS ET OPTIMA DISCIPLINA": APROXIMAÇÕES SEMÂNTICAS EM TORNO DE ATRIBUTOS QUE SUGEREM QUALIDADE
}

\author{
Marcello José Gomes Loureiro \\ Capitão de Corveta (IM). \\ Pós-doutorando, Programa de Pós-graduação em História da Universidade Federal Fluminense. Doutor em História Social, pelo Programa de Pós- \\ graduação em História Social da UFRJ, e doutor em História e Civilização, pela École des Hautes Études en Sciences Sociales (EHESS-Paris). \\ E-mail:marcello.loureiro@marinha.mil.br
}

Ordem, prontidão e regularidade, constituintes atualmente do lema da Pagadoria de Pessoal da Marinha, não são termos gratuitos ou desprovidos de intensa carga semântica e simbólica. Sintetizam, mais profundamente, aspectos fundamentais de um paradigma político-jurídico-cultural que prevaleceu nas monarquias da Europa do sul, especialmente as ibéricas, durante extenso interregno, desde a Idade Média, permanecendo na modernidade dos séculos XVI a XVIII.

Emúltima instância, tais termos apontam para a própria noção de "propriedade, atributo ou condição das coisas ou das pessoas capaz de distingui-las das outras e de thes determinar a natureza" ou, numa única palavra, indicam a qualitas ou a qualidade, neste caso, da instituição a que se referem.' Ordem, prontidão e regularidade são expressões que operavam então como preceitos ou atributos que sugerem qualidade, esta em acepção extemporânea.

Por ocasião de uma reflexão acerca da ideia de qualidade, este artigo tem por finalidade mais ampla propor uma aproximação semântica dos três atributos acima enunciados, procurando demonstrar como são capazes de representar e indicar tal ideia, respeitando, contudo, o contexto histórico-cultural em que se inscreviam. Não custa lembrar que, pelo decreto de 13 de maio de 1808, o Príncipe Regente D. João instituía, no Brasil, um pagador, que deveria exata-

CUNHA, Antonio Geraldo. Dicionário Etimológico da Língua Portuguesa. Rio de Janeiro: Nova Fronteira, 21997, p. 650. mente agir sob os preceitos da "ordem, prontidão e regularidade", legados de um paradigma cultural anterior, como se demonstrará adiante. A hipótese ora desenvolvida éa de que a relativização analítica, ainda que breve, do significado de tais preceitos ao contexto de origem pode contribuir para sua compreensão mais refinada.

O itinerário do texto foi organizado da seguinte forma: numa primeira parte, procurou-se localizar os termos que balizam a condução das reflexões sugeridas, desvelando as matrizes e estilos culturais que modulavam o contexto em questão, centrado mormente nos séculos XVI a XVIII. Alguns exemplos advindos da arte e da literatura foram ser avocados, sem pretensão de alcançar a exaustividade. Na segunda parte, debruçou-se sobre a presença da guerra na configuração do mundo moderno, evidenciando a atividade do abastecimento e, mais nomeadamente, do pagamento. A conclusão consiste menos no resultado cristalizado desse percurso analítico, e mais na propositura de alguns caminhos a delinear.

\section{ORDEM, PRONTIDÃO E REGULARIDADE: UMA TRÍADE E SUAS POSSÍVEIS ACEPÇÕES}

De antemão, cabe examinar mais detidamente as acepções que essa tríade de termos podia admitir em conformidade com o primeiro dicionário da língua portuguesa, escrito provavelmente na segunda metade do séculoXVII, paradoxalmente por um padre francês, Raphael Bluteau. Os magistrais volu- 
mes do Vocabulário Portuguez e Latino, ${ }^{2}$ como resumidamente se intitulou, foram publicados entre 1712 e 1728, em Portugal, reunindo todas as licenças então necessárias. De maneira geral, a tríade compartilhava um eixo semântico que se pode fundar na ideia mais abrangente de conservação e de segurança: (1) ordenada e hierarquizada, que reflete uma "disposição [dispositivo] assento ou colocação das coisas no lugar"; 3 Nessa senda, um adágio antigo sugeria: "não há cousa mais bela em todo gênero de vida que a ordem [que] nele se guarda";; outro dizia: "dai ordem aos vossos negócios porque pouco tempo vos fica de vida". $A$ ausência de ordem, por sua vez, tendia a desvelar perturbação, inquietação e tumulto. ${ }^{6}$ (2) Dotada de presteza ou celeridade, signos de atividade que não se retarda em face dos percalços do tempo? (3) Finalmente, regular, igual e uniforme; que é harmônico e para tanto se submete a uma disciplina optima ou severa. ${ }^{8}$

0 interessante é que a "regularidade" podia ser aproximada a uma "arte",já que "o movimento do relógio deve à arte do relojoeiro toda a sua regularidade", enquanto que o advérbio "regularmente" se explicava como aquilo cujo funcionamento estava adimplido segundo às "regras da arte". Conforme ainda o que ensina Bluteau, a própria noção de arte nos séculos XVII e XVIII podia ser traduzida como "regras e método, com cujas observações se fazem obras úteis, agradáveis e necessárias à Re[s]pública". ${ }^{\prime \prime} \mathrm{A}$ arte dependia ao menos de ordem e regularidade, portanto. Pagar assemelhava-se a uma arte?

\section{1.1. 0 tempo da conservação}

Os três termos ainda se articulam a uma cultura política de espectro mais dilatado, típica da modernidade dos séculos XVI aXVIII, caracterizada pela historiografia especializada como "juridizada", devido à centralidade do direito e de elementos da ética e da moral na edificação de discursos políticos." Nessa cultura, preconizava-se a subordina-

2 BLUTEAU, Raphael. Vocabulário português \& latino: áulico, anatômico, arquitetônico, etc Coimbra: Colégio das Artes da Companhia de Jesus, 8 Vols., 1712 - 1728.

3 BLUTEAU, op. cit., Vol. VI, p. 102. Disponível em http://dicionarios.bbm. usp.br/pt-br/dicionario/1/ordem. Todas as consultas aos dicionários abaixo elencados foram realizadas 27 de novembro de 2017.

4 Ibidem, p. 103

5 Ibidem, p. 104

6 Ibidem, p. 103

7 BLUTEAU, op. cit., Vol. VI, p. 774. Disponível em http://dicionarios. bbm.usp.br/pt-br/dicionario/1/prontid\%C3\%A30

8 BLUTEAU, op. cit., Vol. VII, p. 206 e seguintes. Disponível em http:// dicionarios.bbm.usp.br/pt-br/dicionario/1/regularidade

9 Ibidem, p. 207

10 BLUTEAU, op. cit., Vol. I, p. 573. Disponível em http://dicionarios. bbm.usp.br/pt-br/dicionario/1/arte

"CARDIM, Pedro. Cortes e Cultura Política em Portugal no Antigo ção dos atos e iniciativas dos homens a uma ordem dada pelo direito natural. Uma ordem, assim, anterior ao tempo, atribuída pela natureza, derivação de um direito divino normalmente insondável à racionalidade humana. A ordem natural do mundo não podia ser posta à prova, nem tampouco afetada por vontades individuais ou coletivas. ${ }^{12}$

Nessa lógica, cabia ao rei, que ocupava a posição cimeira do corpo político e social, oferecer justiça, traduzida como garantia de harmonia e segurança (jurídica) às partes da sociedade, impedindo que elas se degenerassem em face dos desgastes do tempo. Toda a cultura político-jurídica não incitava a mudança ou a novidade, mas sim a conservação das coisas e a manutenção dos equilíbrios, provenientes de um jusnaturalismo de matriz escolástica. ${ }^{3}$

Em diálogo com essa matriz teórica, e interessado em associar as ações humanas e a imunidade ao tempo, o humanista flamengo Justo Lípsio escreveu em 1584 um tratado político intitulado Sobre a Constância, em que defendia que da conjugação da firmeza interior dos homens e da administração zelosa da justiça régia decorria a lealdade e obediência estoica por parte dos vassalos, asseverando assim um caminho eficaz para a conservação das monarquias. ${ }^{14}$

A preocupação com a conservação das coisas como são, acreditadas como estavam desde sempre pela força invencível do direito natural, também pode ser percebida a partir da observação de alguns símbolos frequentes que designavam perenidade, ou mesmo eternidade. Um deles era o círculo ou a circunferência, tão comum na arquitetura bramantesca. Do mesmo que um ponto qualquer na circunferência, a eternidade é

constante no ser, que nem vai, nem vem [...], nem se adianta, nem retrocede, nem cede, nem precede, nem sucede [...]. É antiguíssima e novíssima, primeira e última, e contudo nem é primeira e [nem a] última; nem antiga primeiro que nova, nem nova primeiro que antiga; po-

Regime. Lisboa: Cosmos, 1998, pp. 9-50; e BICALHO, Maria Fernanda. "As Tramas da Política: Conselhos, secretários e juntas na administração da monarquia portuguesa e de seus domínios ultramarinos", in FRAGOSO, João \& GOUVÊA, Fátima. A Trama das Redes. Política e negócios no império português. Séculos XVI-XVIII. Rio de Janeiro: Civilização Brasileira: 2010, p. 343-371.

12 XAVIER, Ângela Barreto \& HESPANHA, António Manuel. "A Representação da sociedade e do poder", in HESPANHA, António Manuel (org.). História de Portugal. O Antigo Regime (1620-1807). Lisboa: Círculo dos Leitores, 1993, pp. 121-145.

13 BASTIT, Michel. O nascimento da lei moderna. São Paulo: Martins Fontes, 2010.

14 MARTÍNEZ, Adolfo Carrasco. "El estoicismo en la política europea, 1570-1615", in RODRÍGUEZ, Antonio Cabeza \& MARTíNEZ, Adolfo Carrasco (coords.). Saber y Gobierno. Ideas y prática del poder en la Monarquía de España (siglo XVII). Madrid: Actas, 2013, pp. 19-63. 
rém antiga, porque nova, porém nova porque antiga; antiga porque sempre foi; e nova porque sempre a mesma; tão antiga, que não pode ter princípio, tão nova, que não pode ter fim. ${ }^{15}$

0 círculo podia também indicar uma corte celestial no paraíso, instância para além do tempo, como o ex-voto pintado entre 1503 e 1523, para Amedeo Menez de Sylvia, quadro atualmente exposto no Palazzo Barberini, em Roma. ${ }^{16}$ Aliás, nos anos 1630, manejando habilmente as regras matemáticas que refinavam a experiência da perspectiva, Pietro da Cortona pintou o célebre teto ilusionista intitulado O Triunfo da Divina Providência neste mesmo palácio, onde representou a imortalidade como uma alegoria cujo icone distintivo era exatamente uma coroa circular de estrelas. ${ }^{17}$ Ainda no Barberini, Andrea Sachi pintou outro teto, uma Alegoria da Divina Sapiência, representando a Eternidade também com um círculo nas mãos..$^{18}$.

Outro elemento interessante era a salamandra, símbolo neoplatônico, que opunha valores do mundo terrestre e celestial, e preconizava a noção de eternidade ou perenidade em face do desgaste invencivelmente provocado pelas inclemências do tempo, já que, supostamente, o réptil dispunha da capacidade de atravessar o fogo sem ser por ele aniquilado. Foi adotada em decoração funerária, como no túmulo do Cardeal Francisco Cennini, falecido em 1645, que repousa na igreja de São Marcello, em Roma. Francisco I adotou a salamandra como emblema pessoal em 1504, antes mesmo de se tornar rei de França. Como atributo régio, normalmente a salamandra se representava acompanhada de um lema que guardava a expressão "notrisco al buono, stingo el reo" (alimento-me do bem, afastado do mal, em livre tradução). ${ }^{19}$ Por fim, vale lembrar que, em Portugal, a obra do Padre Fernando de Oliveira, A Arte da Guerra no Mar, impressa em Coimbra, em 1555, trazia em seu frontispício uma salamandra coroada. ${ }^{20}$

15 BLUTEAU, op. cit., Vol. III p. 352. Disponivel em http://dicionarios bbm.usp.br/pt-br/dicionario/1/eternidade

16 The Vision of the Blessed Amedeo Menez de Sylvia (óleo sobre tela, $277 \times 320 \mathrm{~cm}$, inv. 1446). Cf. ONORI, Lorenza Mochi \& VODRET, Rossella. Guide to the National Gallery of Ancient Art Palazzo Barberini. Roma: Pallazzo Barberini, 2012, p. 39.

17 ARGAN, Guilio Carlo. História da Arte Italiana. Vol. 3. São Paulo: Cosac \&Naify, 2003, p. 312-313.

18 LO BIANCO, Ana. La Volta di Pietro da Cortona. Roma: Galleria Nazionale d'Arte Antica di Palazzo Barberini, 2008, especialmente pp. 16-18 e 25 e seguintes.

19 FALCIANI, Carlo. “La galerie François ler: clefs de lecture d'un decor royal", in Dossier de L'Art, n 204, (Le roi François ler et l'artiste Rosso Fiorentino), 2013, pp. 36-58, especialmente p. 39.

20 OLIVEIRA, Fernando de. Arte da Guerra no Mar. Novamente escrita por Fernando de Oliveira e dirigida ao mui magnifico senhor Dom Nuno da Cunha, capitão das galés do muito poderoso Rei de Portugal
A Folha de Acanto também pode ser subsumida nesse ideário da conservação e eternidade. Desde a Antiguidade Clássica, foi largamente utilizada como elemento decorativo. Na Grécia antiga, o Acanto era empregado para distinguir as barracas dos "oficiais encarregados de gerir as finanças", que dispunham de "honras de magistrado e detentores da confiança do rei".21 Mais tarde, em razão de suas pretensas propriedades naturais, acreditava-se que seria capaz de eliminar venenos de cobra e escorpião; por isso, foi confundida como símbolo de imortalidade, sendo até mesmo empregada em arte sepulcral a partir do século XIV, como elemento que anunciava a esperança da ressureição e da vida eterna. ${ }^{22}$

\section{- 1.2. 0 tempo da mudança}

Ao reverso, quando são elencados fatores que se alinham com a noção de desordem ou mudança, (especialmente a imprevisível ou incontrolável, aquela advinda das astúcias da fortuna), ou fatores que supostamente podem auxiliar a ação do tempo e das transformações, percebe-se uma conotação negativa. Por exemplo, a noção de sabedoria, cuja referência máxima costumava ser o rei bíblico Salomão, inicialmente foi compreendida como uma espécie de atributo divino, talvez devido à influência platônica, graças aos escritos de Cícero e Sêneca. Mais tarde, transformou-se em uma virtude, aliás essencial para o exercício da justiça e da prudência, identificando-se com a ideia de instrução. ${ }^{23}$ Assim, admitiu uma complexa dinâmica, já que ela própria assumia um caráter efêmero, porque superável no decorrer do tempo, a ponto de no Portugal do século XVII ser referida como a mais inconstante e volátil das virtudes.

A ideia de movimento, que de modo inerente impede a estabilidade, analogamente era considerada prejudicial. Basta lembrar aquilo que se escreveu (ou que se encomendou que escrevessem) no Discurso Histórico e Politico sobre a sublevação que nas Minas [Gerais] houve no ano de 1720.0 autor (provavelmente mais de um) lembrava que a única certeza concernente às Minas Geras, recém ocupadas, era a de que sua população tinha propensão para se rebelar, porque afinal era sua "gente intratável,

Dom João terceiro. [Coimbra, 1555]. Lisboa: Edições 70, 2008, p. 139.

21 BRASIL. Corpo de Intendentes da Marinha. História da Intendência da Marinha: do ingresso da $1^{\text {a }}$ Turma de Intendentes na Escola Naval aos dias atuais. Textos e pesquisa de Fabíola Maria da Silva Chagas e Patrícia de Andrade Ferreira Braga. Rio de Janeiro: SDM, 2014, p. 31.

22 FRAGOSO, D. Mauro Maia(OSB). "História, iconografia e semiologia da Igreja Abacial de Nossa Senhora do Monserrate do Mosteiro de São Bento do Rio de Janeiro", in Revista Coletânia, Ano XV, n² 29, pp. 179-212, jan-jul. 2016, especialmente p. 185.

23 KRYNEN, Jacques. L'empire du roi. Idées et croyances politiques en France (XIIle-XVe). Paris: Gallimard, 1993, p. 204-217. 
sem domicílio, e ainda que está em contínuo movimento, é menos inconstante que os seus costumes".24

A concepção de sorte, entretanto, como fator capaz de promover rupturas drásticas e imprevisíveis, podia aparecer de modo ainda mais incisivo. Nos escritos da Beuern medieval, é possível encontrar caracterizações negativas acerca da sorte, como nestes versos: "Bruta sorte,/ és de morte:/ tua roda é volúvel,/ benfazeja,/ malfazeja,/ toda sorte é dissolúvel./ Disfarçada/ de boa fada,/ minha ruína sempre queres;/ simulando/ estar brincando/minhas costas nuas feres".25 Em Portugal, para evocar mais uma vez o padre Raphael Bluteau, a sorte podia ser entendida, em suma, como: "tudo que sucede acaso, sem princípio certo, nem causa conhecida"26 A sorte podia agredir noções como ordem, prontidão e regularidade. Referindo-se às detestáveis possibilidades de transformação tempestiva advindas da sorte, assim Bento Teixeira escreveu em sua Prosopopéia, em 1601 :

○ O sorte tão cruel como mudável

- Por que usurpas aos bons o seu direito?

- Escolhes sempre o mais abominável,

- Reprovas e abominas o perfeito.

- O menos digno fazes agradável,

- O agradável mais, menos aceito.

- Ó frágil, inconstante, quebradiça,

- Roubadora dos bens e da Justiça! ${ }^{17}$

\section{A INTENDÊNCIA, A GUERRA E O ESTADO}

Reconhecida como ícone de eternidade nos séculos $X V I$ a XVIII, a Folha de Acanto mais tarde, em 1934, foi adotada como símbolo dos Oficiais Intendentes. ${ }^{28}$ Poderia ser interpretada como a capacidade de os intendentes perpetuarem a conservação das forças militares nos campos de batalha, já que são os maiores responsáveis pela logística.

Desnecessário lembrar que a valorização dos procedimentos de que atualmente chamamos sinteticamente de intendência é indissociável dos processos mais alargados de conformação dos ditos "Estados Modernos". Não perfeitamente ou não apenas devido à complexificação das

24 Discurso histórico e político sobre a sublevação que nas minas houve no ano de 1720. Estudo crítico de Laura de Mello e Souza. Belo Horizonte: FAPEMIG, 1994, p. 59

25 Sobre tais versos, consultar: Carmina Burana: Canções de Beuern. Apresentação de Segismundo Spina, introdução e tradução de Maurice van Woensel. São Paulo: Ars Poética, 1994, p. 175-176.

26 Cf.BLUTEAU, Raphael. Vocabulário Portuguez \& Latino. Disponível em: http://www.brasiliana.usp.br/dicionario/1/sorte.

27 Cf. TEIXEIRA, Bento. Prosopopéia: Lisboa, 1601, estrofe XXXV.

28 Decreto $n^{\circ} 20.240$, de 23 de julho de 1934, instituído pelo Presidente Getúlio Vargas, cf. História da Intendência da Marinha, op. cit., p. 31. próprias estruturas do Estado - a exemplo daquelas costumeiramente tipificadas, como a imposição de um sistema de arrecadação tributária, ou a organização de exércitos e marinhas profissionais, capazes de dotar o Estado do monopólio da violência legítima - mas simples e essencialmente pela necessidade de fazer a guerra. A guerra e sua condução nem sempre eram matéria exclusiva do Estado, já que muitas vezes não era capaz de efetivá-las sem complexos arranjos sociais que abarcavam diversos mecanismos políticos e financeiros, bem como distintos segmentos sociais. ${ }^{29}$

A guerra, todavia, dispôs de papel central no longo e irregular processo de formação dos Estados, a ponto de alguns autores defenderem que os Estados nasceram devido à necessidade imperativa de oferecer proteção às suas populações. ${ }^{30} \mathrm{~A}$ partir da guerra, refinou-se a experiência da administração financeira e tributária. ${ }^{31}$ Outros insistiram que as localidades e os centros de poder das monarquias se tocavam naquilo que dizia respeito às atividades militares e fiscais, essas estritamente interdependentes. No fim, o monarca intencionava conservar sua casa no trono, bem como dispor de reputação no cenário internacional..$^{32} \mathrm{Com}$ propriedade, Immanuel Kant anotou no final do século XVIII que haveria entraves para a consecução perpétua da paz, já que era a guerra que trazia glória e reputação aos reis, sem que eles tivessem de "perder o mínimo dos seus banquetes, caçadas, palácios de recreio, festas cortesãs, etc".33

$\mathrm{Na}$ tratadística militar, Maquiavel insistia que a remuneração era instrumento indispensável para o exercício da guerra, uma vez que ingrediente chave para motivação dos soldados. ${ }^{34}$ É pertinente salientar que a remuneração se configura como uma das atividades mais nevrálgicas de qualquer organização. Traduz-se pela oportunidade em que a instituição (naquele caso, a monarquia ou o rei) reconhece, explicita e remunera o valor dos serviços prestados pelos seus componentes

29 BÉGUIN, Katia. Financier la guerre au XVIle siècle. La dette publique et les rentiers de l'absolutisme. Paris: Champ Vallon, 2012, especialmente pp. 259-341; e DORES COSTA, Fernando. A Guerra da Restauração. 1641-1668. Lisboa: Livros Horizonte, 2004, passim.

30 TILLY, Charles. Coerção, Capital e Estados Europeus. São Paulo: Editora da USP, 1996, passim; e MORRIS, Christopher. Um Ensaio sobre o Estado Moderno. São Paulo: Landy, 2005, passim.

31 CORVISIER, André. A Guerra - Ensaios Históricos. Rio de Janeiro: BIBLIEX, 1999

32 PUJOL, Xavier Gil. "Centralismo e Localismo? Sobre as Relações Políticas e Culturais entre Capital e Territórios nas Monarquias Europeias dos Séculos XVI e XVII", in Penélope: Fazer e Desfazer História, N. 6, Lisboa, 1991

33 KANT, Immanuel. Para a Paz Perpétua. Lisboa: Edições 70, s/data, p. 128-129.

34 MAQUIAVEL, Nicolau. A arte da guerra. Tradução e notas de Eugênio de Morais. Porto Alegre: L\&PM, p. 200. 
(naquela oportunidade, vassalos) permitindo que se consolidem vínculos de reciprocidade e sentimentos de pertença.

Contudo, ao longo dos séculos XVI-XVIII, nem sempre a remuneração ocorria a partir dos cânones atuais, sendo mesmo locupletada graças a saques e pilhagens; por vezes, era levada a cabo de modo improvisado, assumindo contornos que atualmente certamente seriam considerados estranhos. ${ }^{35}$ Tratava-se assim do butim de guerra. Napoleão Bonaparte, ao se referir à guerra que desenrolou na Espanha, reconheceu certa vez que era necessário "retirar a ordem de cobrar uma contribuição [...] para obter os recursos necessários para alimentar, remunerar e vestir seu exército". Ao contrário, percebeu que seria mais conveniente, nesse caso, "compreender que a guerra da Espanha exige esse aumento de forças, que já não posso mais enviar dinheiro; que a guerra deve alimentar a guerra".36

Clausewitz, referência incontornável para a teorização da guerra, denominou esse mecanismo essencialmente de "abastecimento à custa do habitante ou da comuna, o que vem a dar na mesma", para o que definiu algumas particularidades. ${ }^{37}$ Tradicionalmente, é considerado o primeiro a se preocupar com as questões logísticas em combate, provavelmente por ter examinado os efeitos drásticos de sua ausência para os exércitos das guerras napoleônicas. Por fim, outro grande teórico da guerra do século XIX, Antoine-Henri Jomini, ao tratar do tema "instituições militares", anotava que uma das "doze condições essenciais que concorrem para a perfeição de um exército" era exatamente "um sistema de recompensas e promoções bem combinado",38

Seja como fosse o meio de pagamento, o importante era que de fato se procedesse, já que era compreendido como uma obrigação, o ato de "dar o que se deve"39 Pagar, aliás, era "satisfazer o credor". Conforme a tradição, pagar...

deriva-se da palavra Pagus, que não só sig-

35 Sobre este aspecto, veja-se o trabalho já publicado nesta Revista: LOUREIRO, Marcello José Gomes. "O Pagamento no 'Brasil-Colonial': algumas dificuldades e problemas", in Revista PAGMAR, v. 3, p. 72-79, 2015.

36 Correspondência de Napoleão a Berthier, general de Brigada do exército da Espanha. Le Havre, a 29 de maio de 1813. Vol. XX, $n^{\circ}$ 16.521, p. 388. Apud. BONAPARTE, Napoleão. Sobre a Guerra. Obra completa, organizada e comentada por Bruno Colson. Rio de Janeiro: Civilização Brasileira, 2015, p. 340.

37 CLAUSEWITZ, Carl von. Da Guerra. São Paulo: Martins Fontes, 1996, p. 425 e seguintes.

38 JOMINI, Antoine-Henri. Précis de l'art de la guerre. Paris: Perrin, 2008 [1839], p. 98.

39 BLUTEAU, Raphael. "Pagamento", in Vocabulário Portuguez e Latino, op. cit., Vol. VI, p. 180. Disponível em http://dicionarios.bbm. usp.br/pt-br/dicionario/1/pagamento nifica aldeia ou lugar, mas também território, ou terras e campos, que vários lavradores tomavam a renda, e como davam aos senhores proprietários das terras chamadas Pagus, os reeditos delas, a ação de satisfazer qualquer dívida foi chamada Pagar. ${ }^{40}$

Afinal, o que estava em jogo era o vínculo entre as tropas e o rei, e a confiança que podiam depositar na instituição régia - um adágio advertia: "o bom pagador é herdeiro no alheio"41

Ao longo do século XVI, foi a monarquia hispânica que promoveu um significativo desenvolvimento da administração militar, profissionalizando aquele que era conhecido como "pagador". Não deveria causar estranheza, se pensarmos que Felipe II se envolveu em guerras sub-reptícias na Europa. Mas já durante o período medieval, havia um "pagador" encarregado de armar, equipar e manter os soldados; para tanto, nem sempre dispunha de recursos advindos diretamente da monarquia, o que importava a necessidade de se imiscuir em redes sociais. No final do séculoXV, acompanhava-se de um "vedor", que "devia comprovar a eficácia das tropas nas paradas", de modo que os pagamentos pudessem ser avalizados. ${ }^{42}$ Depois, na centúria seguinte, esse sistema de pagamento foi aprimorado com a instituição de um "contador", que cuidava do provisionamento de recursos. Subordinavam-se, todos, a uma Contaduria Mayor de Cuentas, residente em Madri, que procurava exercer algum controle sobre o conjunto das forças militares.

0 termo intendente, contudo, tem acepção mais frequente no século XVIII; suas competências, ainda que pudessem experimentar conflitos jurisdicionais, compreendiam atribuições de matérias militares e de justiça, governo e fazenda. Ainda na Espanha, em 1766, o rei Carlos III segregava melhor suas funções, transmitindo-as parcialmente aos corregedores, conservando-as de guerra e fazenda. ${ }^{43} \mathrm{Na}$ França, a separação dos intendentes das províncias para os intendentes de guerra só se verificou, efetivamente, após a eclosão da Fronda (1648), ainda que o Cardeal Richelieu e Luís XIII tenham concentrado alguma atenção nos procedimentos de intendência. ${ }^{44}$

Em Portugal, a palavra intendente, porém, não se afigura no dicionário do padre Raphael Bluteau. 0 cargo de Intendente

40 Ibidem, Vol. VI, p. 181. Disponível em http://dicionarios.bbm.usp.br/ $\mathrm{pt-br/dicionario/1/pagar}$

${ }^{41}$ Ibidem, Vol. VI, p. 180. Disponível em http://dicionarios.bbm.usp.br/ pt-br/dicionario/1/pagamento

42 BARCELÓ. Juan Laborda. "Pagador", in RUIZ, Enrique Martínez (dir.) Diccionario de Historia moderna de España. Vol. II (Administración). Madrid: Istmo, p. 28.

43 PLANAS, Xavier Alvarado. "Intendente", in RUIZ, op. cit., p. 217.

44 "Administration Militaire" e "Intendance", in CORVISIER, André. Dictionaire d'art et histoire militaires. Paris: Puf, 1998, pp. 9-12 e 467-472. 
da Marinha e seus Armazéns Reais foi criado no reinado de D. José l, em 1770, ${ }^{45}$ muito embora cargos de natureza similar já existissem, a exemplo do cargo de Intendente das Minas, criado pouco depois da descoberta do ouro em Minas Gerais. No dicionário de 1789, de autoria de Antônio de Moraes Silva, a palavra intendente aparece como sinônimo de "entendente" (sic). ${ }^{46}$ Já no Dicionário da Língua Brasileira (sic), publicado pós-independência, em 1832, de Luís Maria da Silva Pinto, o verbete aparece definido como "o que tem a seu cargo o entender, tomar alguma cousa de a dirigir, etc". Luís Maria esclarece ainda que "o uso prevaleceu na ortografia dessas duas palavras, pois parece que se deveria escrever entendencia (sic), entendente".47 Malgrado a expressão intendente marcar sua ausência no primeiro dicionário da língua portuguesa (de Bluteau), na "Guerra de Restauração" contra Castela, no final da década de 1640, um conselheiro do Conselho de Guerra entendia que "a fazenda sempre foi o nervo da guerra", explicitando perfeita consciência das atividades de intendência. ${ }^{48}$

\section{CONSIDERAÇÕES FINAIS}

Como já houvera percebido o Conselho de Guerra luso, no século XVII, ou Jomini, no XIX, dentre tantos outros, não há dúvida de que a capacidade de se conservar na guerra dependia das atividades militares que ao menos desde o final dos setecentos são designadas sob o vocábulo "intendência".

Ao nível das experiências, entretanto, a prática demonstrava que a guerra era uma circunstância-limite, que de modo extremo e violento podia subverter as ordens conhecidas, bem como favorecer a desgraça ou ascensão de indivíduos, famílias e Estados. ${ }^{49}$ Mas, de modo geral, no discurso e na teoria política, infere-se que, quando a guerra era indesejável, logo aparecia caracterizada como "caminho certo para a ruína". Por outro lado, quando era justificada (guerra justa - ius bellum), defendia-se que tinha por finalidade a paz, estrutura anterior, idealizada como se permanente fosse. A guerra então figurava como necessidade invencível, porque a ela cabia restituir à realidade

45 História da Intendência da Marinha, op. cit., p. 24.

46 MORAES SILVA, Antônio. Dicionário da Língua Portugueza, Vol. II, p. 171. Disponível em http://dicionarios.bbm.usp.br/pt-br/ dicionario/2/intendente

47 SILVA PINTO, Luís Maria. Diccionario da Língua Brasileira, Volume único. Verbete Intendente. Disponivel em http://dicionarios.bbm. usp.br/pt-br/dicionario/3/intendente

48 Decreto del-rei ao Conselho de Guerra, de 3 de março de 1649, in Sinopse dos Decretos Remetidos ao Extinto Conselho de Guerra, p. 211-213. Apud LOUREIRO, Marcello José Gomes. lustitiam Dare. A Gestão da Monarquia Pluricontinental: Conselhos Superiores, pactos, articulações e o governo da monarquia pluricontinental portuguesa (1640-1668). Rio de Janeiro: PPGHIS-UFRJ; Paris: EHESS, 2014 (Tese de Doutorado).

49 CORVISIER, A Guerra... op. cit., pp. 252-272. uma condição prévia, de status quo, de justiça e abundância, que foi agredida por uma conjuntura estranha, e que por isso mesmo precisava ser combatida, de modo imperioso, mesmo que sob uso da força. Nesse caso, o encadeamento das palavras e a confecção lógica dos sentidos merece ser repisada: ainda que na prática a guerra possa ser agente incontrolável de mudança, figurava, semiologicamente, como instrumento e garantia última de conservação.

Uma última palavra ou advertência. "Qualidade" foi empregada nestas páginas em sua definição atual, portanto extemporânea ao contexto histórico de que essas análises se ocupam. A solução, como se verifica, foi aproximar-se da ideia de qualidade, demonstrando como a cultura da modernidade valorizava e premiava os atributos de ordem, presteza e disciplina, de que decorriam conservação e segurança.

A própria definição de qualidade ${ }^{50}$ para aquele tempo inexiste de forma precisa: Bluteau reconhece que "nas escolas dos filósofos tem esta palavra muitas e muito diversas acepções"."I Referia-se, provavelmente, a questão dos universais, que ganhou impulso cognitivo graças à Escola de Chartres, a partir do século XII. ${ }^{22} \mathrm{~A}$ exegese medieval discutia se as qualidades incidiam de forma contundente na essência das coisas e pessoas, ou se essas eram imutáveis, restando às qualidades mero papel de nomes (escola nominalista). Tanto é assim que Bluteau continua: "algumas vezes toma-se [qualidade] por aquela razão que determina a própria essência da coisa"; portanto assim, uma "qualidade essencial". De modo distinto, "quando a qualidade determina algum ente exteriormente, e fora da essência, então chama-se qualidade acidental". Arrematava o padre francês com a proposta de uma definição ambivalente... "a muitos mais agrada esta definição: qualidade é um acidente absoluto, que aperfeiçoa a substância, assim no obrar, como no ser. Mas é preciso confessar que não se pode perfeitamente definir a qualidade". Insuficiente a conceituação, tipificava, a seguir, a qualidade em incontáveis categorias binomiais e antitéticas, típicas do pensamento escolástico-tomista (qualidades espirituais e corpóreas; ativas e passivas; manifestas e ocultas, etc).

Mesmo contemporaneamente, do ponto de vista filosófico, "a noção de qualidade é extensíssima e dificilmente pode ser reduzida a um conceito unitário. Podemos dizer

\footnotetext{
50 Aqui, qualidade em sentido lato, já que frequentemente qualidade aparecia vinculada à dignidade ou "qualidade de sangue", ou seja, nobreza.

51 BLUTEAU, Raphael. "Pagamento", in Vocabulário Portuguez e Latino, op. cit., Vol. VII, p. 9. Disponível em http://dicionarios.bbm. usp.br/pt-br/dicionario/1/qualidade

52 GILSON, Étienne. A Filosofia na Idade Média. São Paulo: Martins Fontes, 2001, p. 315 e seguintes.
} 
que ela compreende uma família de conceitos que tem em comum a função puramente formal de servir de resposta à pergunta [...] qual?"53

Da multiplicidade de respostas aceitáveis para essa questão, é possível elencar, para a atualidade, além da própria ideia de conservação e segurança, legado das experiências anteriores, ${ }^{54}$ os parâmetros de eficácia e eficiência, controle de processos, finalidade e transparência.

53 "Qualidade", in ABBAGNANO, Nicola. Dicionário de Filosofia. São

Paulo: Martins Fontes, 2003, p. 816.

\section{Como citar este documento:}

LOUREIRO, Marcello José Gomes. "Dispositio, celeritas et optima disciplina": aproximações semânticas em torno de atributos que sugerem qualidade. Revista PAGMAR, Rio de Janeiro, v.6, n. 6, p. 6 - 12, jan./dez. 2018.

\section{Digital Object Identifier (DOI): 10.4322/pagmar.2446-4791.2018.002}

Recebido em 28JUN2017. Última versão recebida em 02SET2017. Aprovado em 250UT2017.

Avaliado pelo sistema Triple Review: a) Desk Review pelo Editor-Chefe; e b) Double Blind Review (avaliação cega por dois avaliadores da área).

Revisão: Gramatical, Normativa e de Formatação.

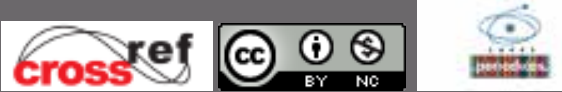

A FHE e a POUPEX oferecem, aos militares da Marinha e seus familiares, condições especiais em poupança, financiamento imobiliário, crédito pessoal, consórcio, seguros e plano odontológico.

\section{NOSSA MISSÃO}

Promover melhor qualidade de vida aos seus clientes, facilitando 0 acesso à casa própria e a seus produtos e serviços

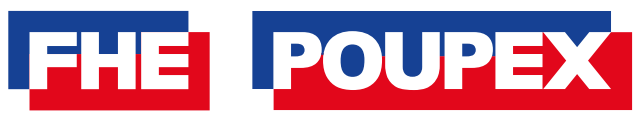

